concentrations were used to estimate dust to fibre conversion factors. Currently a job-exposure matrix is being developed to translate individuals' job histories into exposure histories for both dust and fibre concentrations. Sverdlovsk region mortality data of cohort members have been ascertained by linkage with medical death certificates recorded at the Sverdlovsk Regional Civil Acts Registration Office. In addition, a comparison of mortality rates in Asbest city and in Sverdlovsk region (19972010) was performed. Further efforts are ongoing to ascertain vital status and migration of cohort members from Sverdlovsk region. A parallel cross-sectional survey aimed at estimating tobacco smoking in current workers and veterans (more than 7000 participants) was conducted.

Conclusion The study will continue through 2019. Given the large size of the cohort, the large proportion of female workers and the detailed exposure data, information obtained in this study will expand knowledge of the cancer burden and prevention potential after chrysotile exposure.

\section{OCCUPATIONAL RESPIRATORY HAZARDS IN THE EMERGING MEDICINAL CANNABIS INDUSTRY IN AUSTRALIA}

${ }^{1}$ Sue Reed, ${ }^{2}$ Maggie Davidson, ${ }^{2}$ Gary Dennis, ${ }^{1}$ Martyn Cross. ${ }^{1}$ Edith Cowan University;
${ }^{2}$ Western Sydney University

10.1136/oemed-2018-ICOHabstracts. 1248

Introduction Recently there has been a rapid development of the international medicinal and recreational commercial cannabis industry. In Australia, the downgrading of Cannabis sativa L. to a Schedule 8 controlled substance, when prepared or packed for human therapeutic use, has heralded the introduction of a local medicinal cannabis industry. This paper will present the findings of a gap analysis which will be used for a later student of exposures.

Methods This project involved a critical review of current approaches to health and safety in the medicinal and recreational cannabis industry in Australia and abroad. The data analysis involved the review of literature related to cultivation and production from the farm through to final product sales, including the policies developed by partner organisations, law enforcement and regulatory agencies, as well as research publications.

Results and discussion Early studies of the hemp fibre production demonstrate a relationship between inhalable dust exposure and respiratory conditions such as byssinosis, chronic asthma and chronic obstructive pulmonary disease (COPD). More recently, attention has focused on the allergenic properties of C. sativa L. pollen exposure, as well as healthy and safety hazards on outdoor recreational cannabis farms in the United States. It is evident that there are multiple biological, physical and chemical hazards associated with cannabis cultivation and manufacturing procedures, some that are inherently unique to the plant. A greater understanding of the aetiological properties of medicinal otherwise referred to as drug or hybrid type, C. sativa L. containing greater than $0.35 \%$ delta 9-tetrahydrocannabinol (THC) content is required to determine if exposure control is required, including the development of an occupational exposure limit (OEL).
1497

REVIEW OF THE RESPIRATORY COMPONENT OF THE QUEENSLAND COAL MINE WORKERS' HEALTH SCHEME

${ }^{1} \mathrm{DC}$ Glass ${ }^{*},{ }^{2} \mathrm{R}$ Cohen, ${ }^{1} \mathrm{M}$ Roberts, ${ }^{2} \mathrm{~K}$ Almberg, ${ }^{1} \mathrm{R}$ Hoy, ${ }^{2} \mathrm{~L}$ Go, ${ }^{1} \mathrm{MR}$ Sim. ${ }^{1}$ Monash University, Melbourne, Australia; ${ }^{2}$ University of Illinois, Chicago, USA

\subsection{6/oemed-2018-ICOHabstracts. 1249}

Introduction Coal miners in Queensland Australia have a preemployment medical and then medical every five years. In 2015, cases of coal workers' pneumoconiosis (CWP) were identified among miners/ex-miners, outside the medical scheme.

Methods We reviewed the respiratory component of the medical scheme and evaluated its design and implementation. We reviewed 91 completed medical forms, 257 chest $\mathrm{x}$-rays (CXRs) and 260 spirograms and surveyed the spirometry equipment and training of providers. We interviewed employer and trades union representatives.

Results Medicals had become focussed on fitness for work rather than surveillance. Some forms were poorly completed and the questions were inadequate to evaluate respiratory health.

The criteria to trigger a CXR were unclear. Only 25\% of the CXRs 'good' under the ILO classification scheme. 18 of the CXRs showed Category 1 simple pneumoconiosis, only two were identified in the original radiology reports.

$40 \%$ of the spirograms had not been performed to ATS/ ERS standards and were uninterpretable. We identified 30 abnormal spirograms of which only 1 had been identified in the medical report. The survey of spirometry providers identified poor knowledge of the equipment, poor quality control processes and inadequate training.

Discussion An effective scheme needed to more clearly articulated its surveillance purpose and to be reviewed on a regular basis. We recommended that a smaller number of experienced doctors trained and approved to undertake these assessments. The scheme needed better spirometry testing and interpretation, a better CXR referral process, improved CXR interpretation and reporting using the ILO criteria. Clinical guidelines were needed to inform diagnosis and management of CMDLD. Medical screening and surveillance is not a substitute for effective dust control, which is the primary protection against CWP. This is particularly important because it can progress even after dust exposure has ceased. These findings have implications for medical screening in other industries.

\section{TRACKING AETIOLOGY AND EXPOSURE FOR IDIOPATHIC LUNG DISEASES: RECENT ADVANCES FROM IN SITU MULTI-ELEMENTAL IMAGING WITH LASER SPECTROMETRY}

${ }^{1,2} \mathrm{~B}$ Busser*, ${ }^{3} \mathrm{M}$ Leprince, ${ }^{3} \mathrm{~S}$ Moncayo, ${ }^{4} \mathrm{~F}$ Pelascini, ${ }^{2} \mathrm{~J}-\mathrm{L}$ Coll, ${ }^{1} \mathrm{~V}$ Bonneterre, ${ }^{2} \mathrm{~V}$ MottoRos, ${ }^{2} \mathrm{~L}$ Sancey. 'Grenoble Alpes University Hospital, 38000 Grenoble, France; ${ }^{2}$ Grenoble Institute for Advanced Biosciences, IAB INSERM U1209 CNRS UMR5309 - Grenoble; ${ }^{3}$ Institute Light and Matter, UMR5306 Univ. Lyon 1-CNRS, 69622 Villeurbanne; ${ }^{4}$ Critt Matériaux Alsace, 67305, Schiltigheim

10.1136/oemed-2018-ICOHabstracts. 1250

Introduction There is a major health problem due to the occupational related exposures to mineral particles, metals, and 